\title{
PENGElolaAN WARISAN BUDAYA DUNIA DI INDONESIA
}

\author{
Tulisan merupakan ringkasan dari makalah \\ yang disampaikan oleh Drs. Socroso MP, M.Hum \\ Direktur Peninggalan Purbakala, Direktorat Jenderal Sejarah dan Purbakala \\ Pada Bimbingan Teknis Pengelolaan Situs Warisan Dunia \\ Borobudur, 3-7 September 2007 \\ Diringkas oleh Arif Gunawan, staf BKP Borobudur
}

Pengelolaan warisan budaya dunia di Indonesia sangat penting dilakukan mengingat besarnya kekayaan budaya yang dimiliki. Kekayaan budaya Indonesia tersebut selain yang telah terdaftar sebagai warisan dunia, banyak yang berpotensi untuk diajukan sebagai warisan dunia. Pertanyaan yang muncul kemudian adalah bagaimana pengelolaan warisanwarisan budaya tersebut. Untuk dapat menjawab pertanyaan tersebut, maka harus dimulai dari pertanyaan yang lebih mendasar, seperti; apa yang dimaksud dengan Warisan? Dan apa yang disebut Warisan Budaya Dunia dan Warisan Alam Dunia?

Warisan sering dijelaskan sebagai peninggalan kita dari masa dahulu, apa yang hidup bersama kita sekarang, dan apa yang akan kita tinggalkan bagi generasi mendatang untuk belajar dari, mengagumi, dan menikmatinya. Warisan Budaya sebagaimana didefinisikan dalam Konvensi Warisan Dunia mencakup:

- Monumen; karya arsitektur, karya patung dan lukisan yang monumental, elemen atau struktur yang bersifat arkeologis,prasasti, gua hunian dan kombinasi yang memiliki nilai universal luar biasa dilihat dari sudut pandang sejarah, seni dan sains

- Kumpulan bangunan:yaitu kumpulan bangunan yang terhubung atau terpisah yang karena arsitektur, homogenitas atau tempatnya dalam landsekap memiliki nilai universal luar biasa dipandang dari sudut sejarah, seni dan sains

- Situs: yaitu lokasi/tempat karya manusia atau karya alam dan manusia dan kawasan yang termasuk situs arkeologis,memiliki nilai universal luar biasa dilihat dari sudut pandang sejarah, estetika, etnologi atau antropologi.
Sedangkan Warisan Alam mencakup:

- Ciri-ciri alam yang terdiri dari bentukan fisikal dan biologis atau himpunannya, yang memiliki nilai universal luar biasa dari sudut pandang estetika atau ilmiah

- Bentukan geologi dan fisiografi yang diuraikan sebagai habitat species hewan dan tumbuhan langka yang memiliki nilai universal luar biasa dari sudut pandang sains dan pelestarian;

- Situs alam atau kawasan yang diuraikan dengan tepat serta memiliki nilai universal luar biasa dari sudut pandang sains, pelestarian atau keindahan alam

Secara lebih luas warisan budaya dan warisan alam tercakup dalam istilah yang disebut Lansekap Budaya (Cultural Landscape). Lansekap budaya merupakan properti budaya dan mewakili "perpaduan antara pekerjaan alam dan manusia" yang merupakan ilustrasi dari evolusi peradaban dan penyebaran manusia dalam pengaruh keterbatasan fisik yang diberikan oleh lingkungan alam disekitarnya serta oleh kekuatan-kekuatan sosial, ekonomi, dan budaya, baik eksternal maupun internal.

Peninggalan budaya dan alam dapat diakui sebagai warisan dunia karena memiliki Nilai Universal Luar Biasa (Outstanding universal value). Nilai universal luar biasa dimaknai sebagai memiliki nilai nilai dari segi budaya dan/atau alam yang sangat luar biasa (exceptional) sehingga melampaui batas nasional serta memiliki arti penting bagi generasi sekarang maupun yang akan datang bagi seluruh umat manusia.

Saat ini cakupan Warisan Budaya Dunia di Indonesia meliputi :

Bendawi (Tangible)

- Kompleks Candi Prambanan 1991 (Prambanan Temple Compound nomor:642)
- Kompleks Candi Borobudur 1991 (Borobudur Temple Compound nomor: 592)

- Situs Prasejarah Sangiran 1996 (Sangiran Eary Man Site nomor 593).

Tak Benda (Intangible)

- Wayang Kulit 2003 (Masterpiece of Humanity)

- Keris 2006 (Masterpiece of the Oral and Intangible Heritage of Humanity)

Lansekap budaya (Culture Landscape)

- Indonesia belum ada - dalam proses penominasian "The Cultural Landscape of Bali"

Satu lagi yang juga diusulkan namun masih dalam proses penilaian dan perbaikan adalah Tana Toraja.

Untuk dapat ditetapkan seagai warisan dunia diperlukan proses nominasi. Proses nominasi warisan dunia mengikuti alur yang cukup panjang. Alur nominasi warisan budaya dunia di Indonesia dimulai dengan adanya Studi Kelayakan. Tahap selanjutnya adalah penyusunan naskah nominasi dan Manajemen Plan. Setelah disosialisasikan dilakukan pengusulan naskah nominasi dan disosialisasikan kembali. Naskah nominasi diadakan revisi untuk selanjutnya dilakukan penetapan nominasi. Langkah selanjutnya adalah implementasi Manajeme Plan. Kemudian diadakan monitoring dan evaluasi.

Dari tinggalan budaya menuju warisan budaya

Tinggalan budaya merupakan keseluruhan segala jenis tinggalan, baik benda maupun tak benda. Semua dapat dikatakan sebagai tingalan budaya, meskipun belum ditetapkan. Tinggalan budaya yang telah ditetapkan sesuai perundang- 
undangan selanjutnya disebut sebagai cagar budaya. Cagar budaya merupakan kekayaan yang dapat dimanfaatkan baik untuk pariwisata, pendidikan, penelitian, dan lain-lain dalam kerangka pelestarian. Cagar budaya yang telah dimanfaatkan distilahkan sebagai sumberdaya budaya. Sumberdaya budaya yang telah menjadi milik kolektif selanjutnya disebut sebagai warisan budaya.

Pelestarian warisan budaya sangat penting karena merupakan Hakekat Data Masa Lalu, dimana warisan budaya tersebut berada dalam Keterbatasan Secara Kuantitas Dan Kualitas. Tinggalan budaya yang dibuat manusia masa lalu tidak seluruhnya yang sampai ke tangan kita karena dipengaruhi oleh beberapa faktor. Tinggalan budaya yang sampai ke tangan kita Cuma sedikit yang dimengerti dan dimanfaatkan

Peraturan yang Terkait Dengan Pengelolaan Warisan Dunia

Pelestarian memerlukan peraturan perundangan, beberapa peraturan yang terkait yaitu:

- Ratifikasi Konvensi Internasional "Convention Concerning the Protection of the World Cultural and Natural Heritage 1972" oleh pemerintah RI pada 6 Juli 1989

- Konvensi Internasional: Conlention of the save guarding the intangible culture of beritage 2003 (belum dilakukan ratifikasi oleh pemerintah RI, konvensi ini efektif mulai 20 April 2006) (saat ini dalam proses diratifikasi sudah selesai)

- Undang-undang No. 5/1992 BCB

- Undang-undang no. 24/1992 tentang Tata Ruang

- Lndang-undang No. 32/2004 tentang (OTCDA

\section{Prinsip Pengelolaan Warisan Budaya Dunia}

Prinsip pengelolaan warisan dunia lang berupa bendawi, tak bendawi, dan lansckap budaya harus meliputi bebcrapa prinsip sebagai herikut:
- Berkelanjutan

- Dapat dimanfaatkan dan dikembangkan

- Sesuai Daya Dukung Ekologis

- Untuk Generasi Berikutnya

- Bernilai Ekonomis

- Dan Berpihak pada Etika dan Sosial Masyarakat

Untuk mewujudkan pengelolaan warisan dunia yang baik diperlukan paradigma pengelolaan yang sesuai dengan tuntutan kekinian. Sehingga diperlukan perubahan paradigma lama ke paradigma baru. Perubahan Paradigma Dalam Pengelolaan Warisan Budaya tersebut dapat dilihat pada tabel 1.

Cakupan Warisan Budaya Dunia tidak hanya situs tinggalan budaya saja, namun meliputi beberapa cakupan lain sebagai berikut :

- Lansekap Budaya (Culture landscape)

- Situs Arkeologi (Arcbaeological Sites)

- Situs Bawah Air (Undervater Sites) (menurut data kita memiliki lebih dari 400 situs BCB bawah air)

- Situs Kota Bersejarah dan Kelompok Warisan Budaya (Historic Urban Sites and Heritage Groups)

- Monumen, Bangunan, dan Struktur (Monuments, Buildings, and Structures)

Hal ini menuntut kita untuk juga mengembangkan pengelolaan bidangbidang cakupan tersebut.
Upaya Pengelolaan Warisan

Budaya Dunia

Upaya pengelolaan warisan budaya

dunia meliputi hal-hal sebagai berikut:

- Pelestarian: perlindungan, pemanfaatan, dan pengembangan

- Pemberdayaan masyarakat--. keterlibatan masyarakat dalam pengelolaan

- Public anarness --- sosialisasi

- Capacity building --- efektifitas kelembagaan

- Coordinating Board --- koordinasi antar stake bolders

- Penegakan hukum dan revisi terhadap UU No 5/1992 tentang $B C B$ dan Penyusunan UU Kebudayaan

Hal-hal yang Diperlukan dalam Pengelolaan Warisan Budaya Dunia adalah:

- Monitoring

- Penilaian

- Mitigasi dan Penanganan Bencana

- Pelestarian: Perlindungan, pemanfaatan, dan pengembangan

- Pengendalian

- Penelitian dan Pengembangan

- Penyusunan Data Base dan Informasi

- Penyusunan standar prosedur dan pedoman dalam pengelolaan serta penanggulangan dampak terhadap Warisan Budaya Dunia

Tabel 1 (UNESCO, 2004)

\begin{tabular}{|c|c|}
\hline Paradigma Lama & Paradigma Baru \\
\hline $\begin{array}{l}\text { Monumen Raja, Pendeta, dan } \\
\text { Politik }\end{array}$ & $\begin{array}{l}\text { I'empat dan Ruang Manusia } \\
\text { Biasa }\end{array}$ \\
\hline Kosong, Situs Matcrial & Masyarakat Bcrkclanjutan \\
\hline Komponen lïis & Tradisi dan Praktck Kichidupan \\
\hline Manajemen $\Lambda$ dministrasi Pusat & $\begin{array}{l}\text { Pembangunan Nassarakat - } \\
\text { pengelolaan bersama Pemerintah } \\
\text { pusat-dacrah-massarakat }\end{array}$ \\
\hline $\begin{array}{l}\text { Penggunaan Iilit (rerutama } \\
\text { lkademis }\end{array}$ & $\begin{array}{l}\text { Penggunaan Populer (l' nouk } \\
\text { Pembanguman berkelanjutan }\end{array}$ \\
\hline
\end{tabular}




\section{Tematik}

Masalah Pengelolaan Warisan Budaya Dunia

Pengelolaan warisan budaya dunia di Indonesia masih memiliki bererapa masalah. Masalah-masalah tersebut harus dipecahkan untuk pengelolaan yang lebih baik di masa mendatang. Beberapa masalah yang masih ditemui dalam pengelolaan warisan budaya dunia di Indonesia adalah sebagai berikut:
Kewenangan

Lemahnya peraturan dan sanksi hukum (regulation and law inforcement)

Kesadaran masyarakat (cultural and social carrying capacity)

Kelembagaan

Tekanan pembangunan (enviromental carrying capacity --bazard)

- Managemen
Pemecahan berbagai masalah diatas memerlukan proses yang panjang karena menyangkut berbagai kepentingan terkait. Proses pemecahan tersebut secara normatif dapat dilihat pada diagram di bawah.@

\section{Proses dalam Pemecahanan Masalah Pengelolaan Warisan Budaya Dunia di Indonesia}
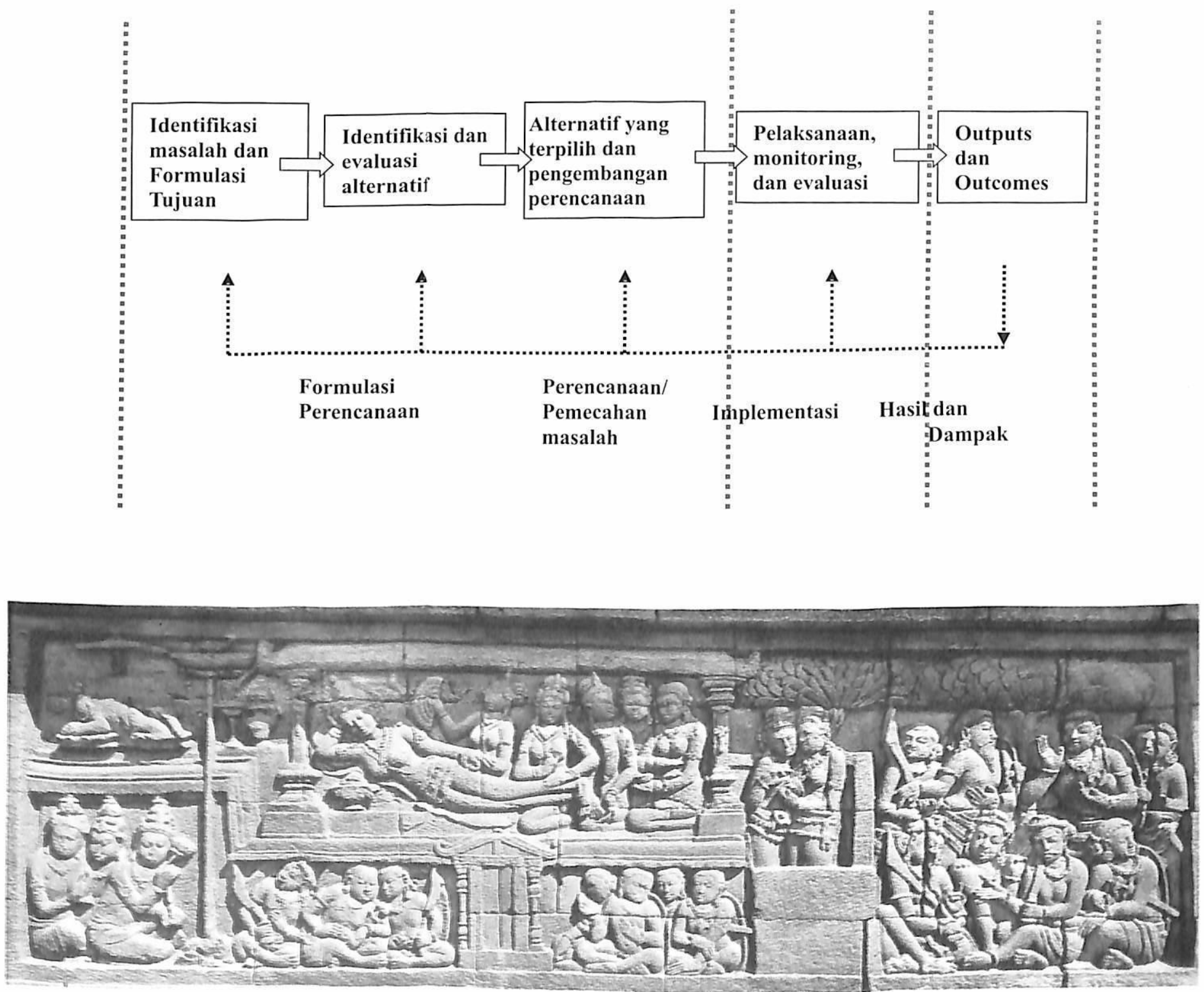

Relief : Dewi maya bermimpi, bahwa seekor gajah putih telah masuk kedalam rahimnya.

Lokasi : Sisi Timur, Dinding Tingkat I relief rangkaian atas bidang $\mathrm{j}$ 